\title{
DESENVOLVIMENTO DE SECADOR SOLAR CONSTRUÍDO A PARTIR DE MATERIAL RECICLÁVEL
}

\author{
I. B. ALMEIDA', M. A. A. LIMA ${ }^{1}$ e L. G. M. SOUZA ${ }^{2}$ \\ ${ }^{1}$ Instituto Federal do Rio Grande do Norte (IFRN) - Campus Mossoró \\ ${ }^{2}$ Laboratório de Máquinas Hidráulicas e Energia Solar - Universidade Federal do Rio Grande do Norte \\ isac.barbosa@ifrn.edu.br*
}

Artigo submetido em outubro/2014 e aceito em abril/2016

DOI: $10.15628 /$ holos.2016.2477

\section{RESUMO}

Este artigo demonstrará uma possibilidade de fabricar um secador solar de exposição direta para a secagem de alimentos, a partir de material reciclável. Dentre os tipos de secador, o que possui exposição direta trabalha em regime de circulação natural de ar. A metodologia está detalhando cada parte do procedimento necessário para construção do secador solar utilizando material reciclável, no caso desse projeto, usou-se sucata de luminária pensando em uma destinação ambientalmente correta. As vantagens desse modelo de secador solar proposto são: baixo custo, de fácil manuseio, procedimento de montagem simples e colabora com o ciclo da reciclagem. Para a comprovação de eficiência do secador foram realizados testes para a secagem de uva no qual seus resultados confirmam a viabilidade térmica e econômica do sistema alternativo de secagem. Vale salientar a importância socioeconômica desse projeto diante da aplicabilidade social por parte da população de baixa renda, obtendo a oportunidade de agregar valor aos produtos alimentícios através da desidratação que representará uma boa opção de geração de renda, visto sua valorização comparada a fruta in natura.

PALAVRAS-CHAVE: secador solar, desidratação, energia solar, material reciclável.

\section{SOLAR DRYER DEVELOPMENT BUILT FROM RECYCLED MATERIAL}

\section{ABSTRACT}

This article demonstrates a possibility of manufacturing a solar dryer for drying direct exposure of food, from recycled material. Among the types of dryer, which has direct exposure works in natural circulation system of air. The methodology is detailing each of the necessary procedure for the construction of solar dryer using recyclable material in the case of this project, he used lamp scrap thinking of an environmentally correct disposal. The advantages of this proposed solar dryer model are: low cost, easy to use, simple assembly procedure and collaborates with the recycling cycle. For the dryer efficiency verification tests were performed for grape drying in which their results confirm the thermal and economic feasibility of the alternative drying system. It is worth noting the socioeconomic importance of this project on the social applicability by the low-income population, getting the opportunity to add value to food products through dehydration which represent a good option for income generation, since its value compared to fresh fruit.

KEYWORDS: solar dryer, dehydration, solar energy, recyclable material. 


\section{INTRODUÇÃO}

O Brasil surge como uma das forças produtoras no terceiro milênio. Ele é um dos três maiores produtores de frutas do mundo. Sua produção superou 43 milhões de toneladas em 2008, o que representa $5 \%$ da produção mundial. Com esse saldo, o País fica atrás apenas da China e da Índia. Segundo o Instituto Brasileiro de Frutas (IBRAF) 53\% da produção brasileira são destinados ao mercado de frutas processadas e $47 \%$ ao mercado de frutas frescas. Existe hoje um mercado externo potencial acessível à fruticultura brasileira de 28,3 milhões de toneladas.

Apesar da indiscutível necessidade de se aumentar a produção de frutas e ampliar as exportações tornam-se imprescindível reduzir as perdas que ocorrem em toda a cadeia produtiva. Nos países emergentes as perdas são estimadas em $50 \%$ para alguns produtos. Nossa realidade não é diferente, desde o produtor até o consumidor, a magnitude das perdas é considerável. Este fato evidencia a urgente necessidade de processos simples e baratos, que possam oferecer caminhos para conservar estes alimentos extremamente perecíveis (Souza et al., 2010).

A utilização da energia solar para a secagem de grãos, frutas e outros produtos alimentícios apresenta-se como uma excelente alternativa para regiões de clima tropical, como o Nordeste.

A secagem é um processo físico que consiste na eliminação de água por evaporação, de modo a melhorar a conservação de um produto. É um dos métodos mais antigos de conservação de alimentos e surgiu quando os povos primitivos observaram que as sementes das plantas, com que se alimentavam, se conservavam por mais tempo depois de expostas ao sol. A partir daí começaram a secar ao sol outros alimentos, nomeadamente carne, peixe e os próprios grãos.

As frutas adquirem uma maior durabilidade através da desidratação ou secagem é um dos processos comerciais mais usados na conservação de produtos agropecuários, sem que eles percam suas propriedades nutritivas. A redução do teor de umidade do produto tem por objetivo evitar a promoção de microrganismos e de reações químicas indesejáveis que podem deteriorar o produto tornando-o impróprio para o consumo (MADAMBA, 2007).

Dentre as vantagens que se destacam pela secagem de frutas está a concentração dos nutrientes e o maior tempo de vida de prateleira, também, o sabor permanece quase inalterado por longo tempo, uma vez que diminui radicalmente a proliferação de microrganismo devido à escassez de água do produto. A secagem é atualmente empregada não apenas com o objetivo de conservação dos alimentos, mas também para elaboração de produtos diferenciados, como por exemplo, as massas, biscoitos, iogurtes, sorvetes entre outros (FIOREZE, 2004).

A secagem de alimentos é um mercado em ascensão e com grande potencial de crescimento e ainda mal explorado pelos empresários brasileiros. (SOUZA, et al., 2007). A secagem utilizando a energia solar demonstra uma alternativa de grande interesse pelas suas qualidades e características de ser limpa, gratuita e de enorme potencial, amplamente disponível em todo o Brasil e principalmente no Nordeste (FERREIRA, et al., 2008).

O secador solar direto é composto por uma só peça que desempenha simultaneamente a função de coletor solar e de câmara de secagem onde a radiação solar incide diretamente sobre o produto colocado no secador. $\mathrm{O}$ ar é aquecido por efeito de estufa, a circulação do ar é feita por convecção natural, a secagem é rápida e os custos são baixos. Os produtos são protegidos das poeiras e insetos.

O critério principal para o desenvolvimento do protótipo foi a simplicidade, de forma que os futuros usuários possam construir o secador utilizando apenas material reciclável. Os 
secadores produzidos têm como principais características o baixo custo e fáceis processos de fabricação e montagem. Podem representar uma alternativa para a produção de alimentos propiciando a minimização da fome de comunidades carentes e, também, uma opção de geração de emprego e renda para essas comunidades a partir da fabricação e comercialização de produtos desidratados.

Este é um detalhe fundamental para a disseminação desta tecnologia e para a sustentabilidade do projeto, uma vez que contribuirá com a população que necessita de uma geração de renda extra, auxiliando na luta contra o desemprego e combatendo a exclusão social.

\section{METODOLOGIA}

Para a construção do secador solar pensou-se na utilização de um material reciclável nesse caso foi utilizado à calha da luminária de lâmpada fluorescente (Figura 1). Devido à mudança das luminárias utilizadas na instituição foram descartadas essas sucatas no qual foram aproveitadas para o desenvolvimento do secador solar, visando uma reutilização do material.

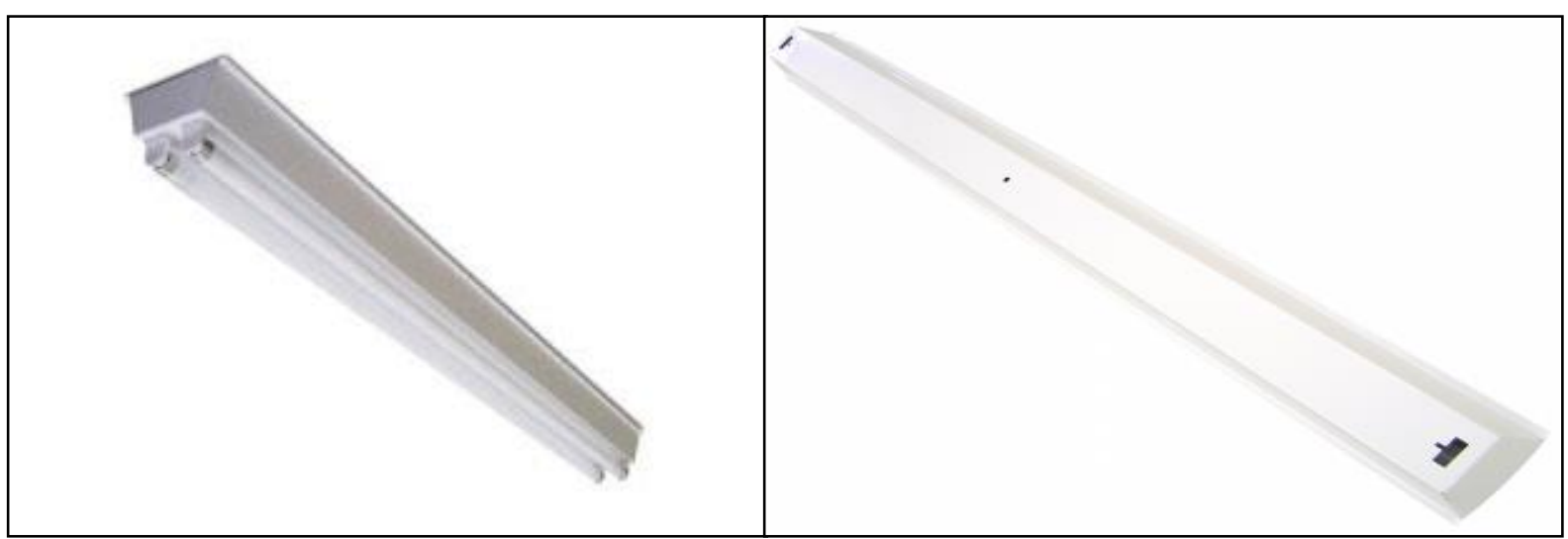

Figura 1 - Ilustração da luminária de lâmpada fluorescente e somente a calha da luminária.

Para a produção do secador solar de exposição direta, o sistema de secagem proposto foi construído a partir de uma sucata de luminária mostrada na figura $2 \mathrm{com}$ as dimensões expostas com detalhes para a melhor reprodução.

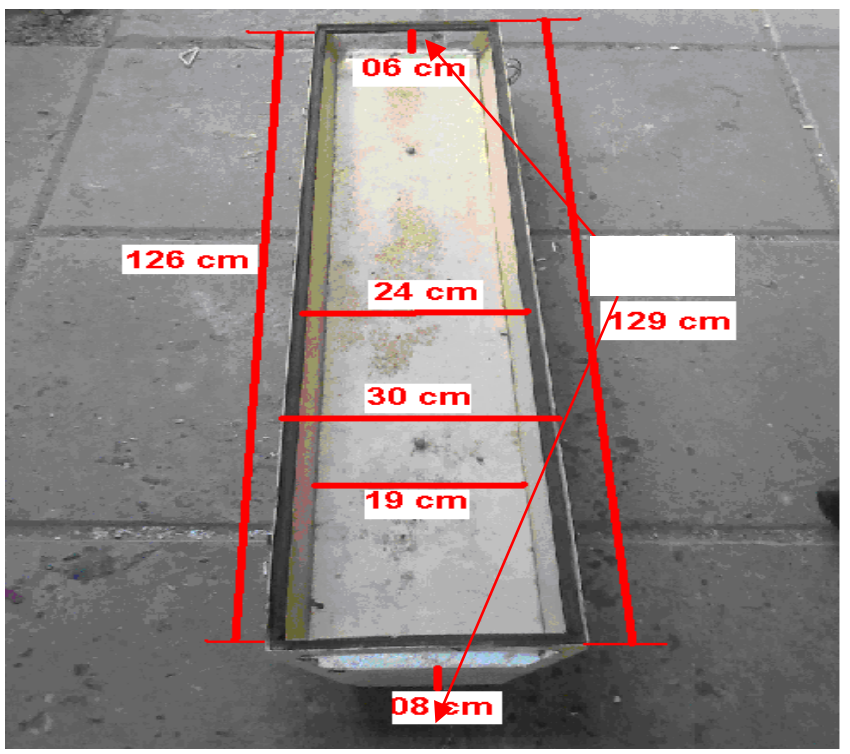

Figura 2. Sucata de luminária utilizada como molde para confecção do secador solar proposto. 
A área interna do secador é onde os produtos são colocados para secar, onde possui uma área de $0,25 \mathrm{~m}^{2}$ e o volume interno de $15 \mathrm{~L}$.

Os procedimentos para a realização do secador se iniciaram com a retirada da fiação e dos componentes elétricos da luminária e posteriormente feito a abertura nas testas do secador para a melhor circulação do ar, através do uso de uma serra manual comum.

Realizado a abertura, cortou-se pedaços de vidros, aproveitados de sucatas de janelas para compor a cobertura e bandeja do secador, através do uso de ferramenta apropriada de diamante. Em seguida, foi efetuado a pintura da chapa sobre a qual foram colocados vidros da bandeja e de todas as superfícies internas do secador com tinta preta fosca, como apresentado na figura 3.

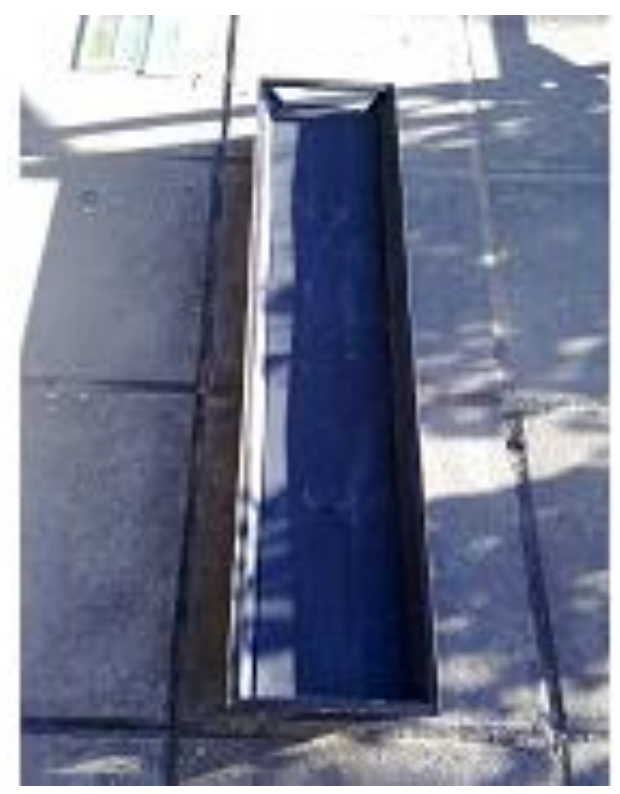

Figura 3. Sucata luminária após corte e pintura.

Após a pintura da chapa, foram colocados os vidros sobre a chapa absorvedora de calor e realizado a pintura das superfícies externas do secador com tinta preta fosca. Finalizando as etapas de produção do secador solar foi colocado o vidro de cobertura, vidro plano com $3 \mathrm{~mm}$ de espessura.

A Figura 4 mostra as várias operações dos processos de fabricação e montagem do secador solar de convecção natural de exposição direta construído.
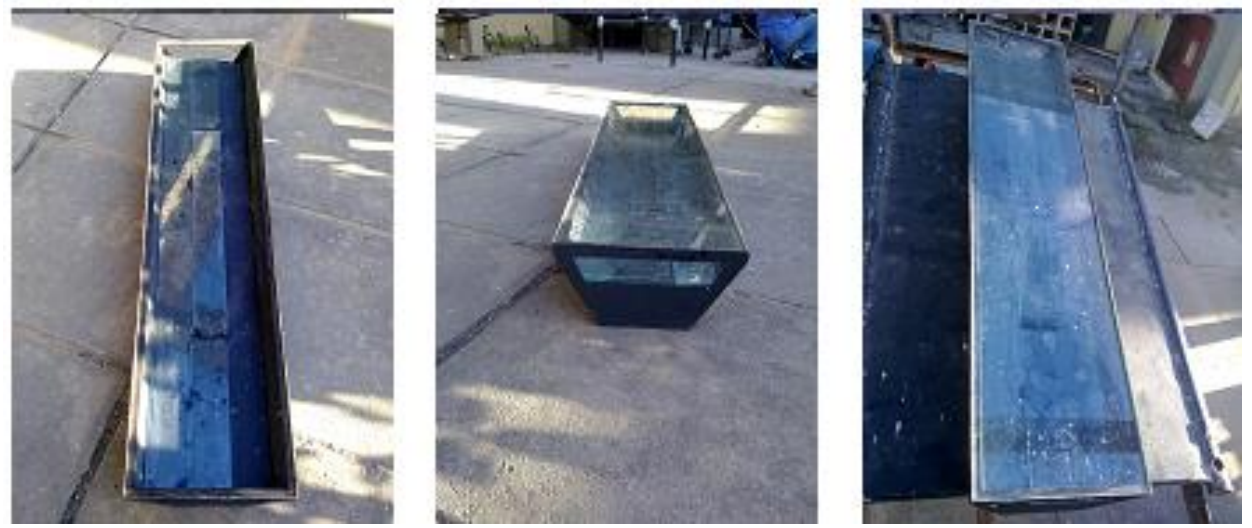

Figura 4. Etapas dos processos de fabricação e montagem do secador solar de compósito proposto.

Com o objetivo de verificar a eficiência do secador, foi realizado o experimento conduzido no Laboratório de Máquinas Hidráulicas e Energia Solar no Núcleo de Tecnologia Industrial da 
Universidade Federal do Rio Grande do Norte. Utilizaram-se em média 960g de uva roxa, que foram higienizadas corretamente, posteriormente cortadas ao meio no sentido longitudinal para serem expostas no secador.

O secador de exposição direta foi ensaiado para secagem da uva em regime de convecção natural, sendo levantados dados de radiação solar global, umidade relativa do ar, temperatura ambiente e massas inicial e final de três amostras, localizadas próximas a entrada de ar, no meio e próxima a saída de ar do secador, a análise foi feita no intervalo de uma hora durante quatorze horas no total. Para a sua identificação, as amostras foram colocadas nos três pontos indicados de forma que ficassem mais distantes das outras, facilitando o seu reconhecimento. A figura 5 ilustra onde as amostras se ficaram expostas nos secadores.

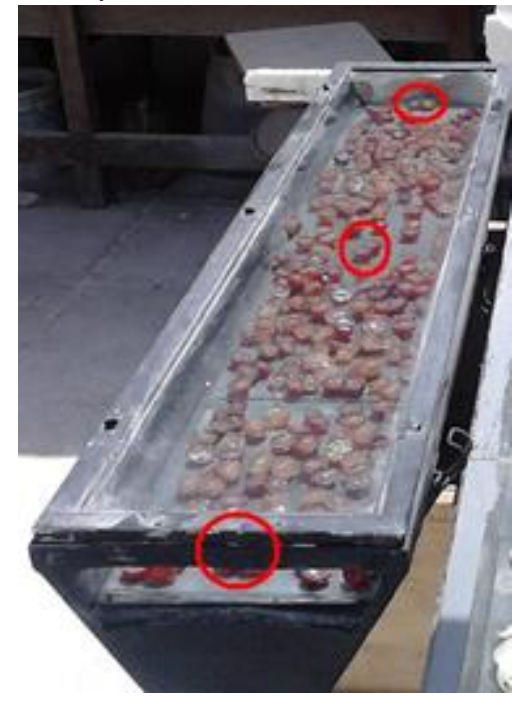

Figura 5. Secador durante ensaio com amostras de uva.

As massas das amostras foram verificadas a cada hora decorrida de secagem. Se o produto a ser seco não atingia sua plena secagem em um dia, retirava-se o produto e colocava-o num recipiente fechado para a manutenção da umidade para a continuação da secagem no dia seguinte.

Dois parâmetros são fundamentais na secagem de quaisquer produtos; a massa de água inicial e a massa de água final pretendida. Em relação ao percentual residual de massa de água a literatura especializada e secagem solar aponta uma faixa de valor de $15-20 \%$.

O teor de umidade, ou o mesmo que teor de água corresponde à relação percentual entre a massa de água presente e a massa total do produto. Os valores de massa de água utilizados na Tabela 1 foram obtidos de acordo com a Tabela Brasileira de Composição de Alimentos (TACO).

Tabela 1. Percentual de água nos alimentos de acordo com a TACO

\begin{tabular}{l|c}
\hline \multicolumn{1}{c|}{ Alimento } & Massa de Água (\%) \\
\hline Uva pré-secagem & 86,1 \\
\hline Uva pós-secagem & 15 \\
\hline
\end{tabular}

A Tabela 1 apresenta o percentual de massa de água presente nos alimentos antes do processo de secagem, chamado de umidade inicial do produto e o percentual de água desejado ao final do processo.

\section{RESULTADOS E DISCUSSÃO}

Foram realizados testes com o sistema de secagem de exposição direta em convecção 
natural para a secagem da uva que foi cortada ao meio longitudinalmente e colocadas sobre a bandeja de secagem como ilustra a figura 6.

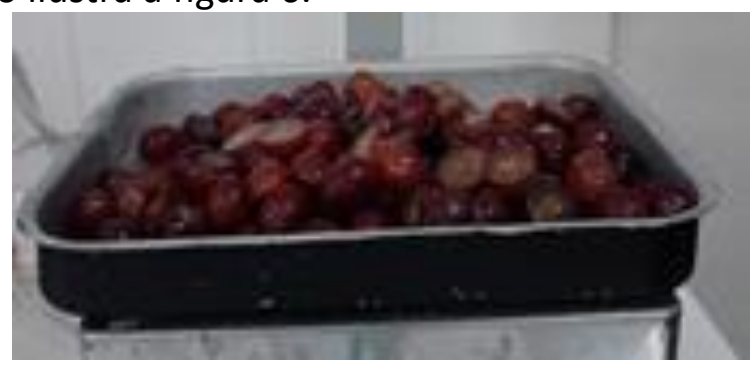

Figura 6. Uvas cortadas longitudinalmente.

A Tabela 2 apresenta os dados gerais da secagem da uva. O percentual de massa úmida da uva corresponde a $86,1 \%$ de sua massa inicial, conforme aponta a literatura de desidratação de alimentos. A massa total da uva antes de secar foi de 961g. A amostra 1 ficava colocada próxima a entrada do secador, a amostra 2 no meio e a amostra 3 próxima a saída do secador, a secagem durou 4 dias.

Tabela 2. Dados gerais da secagem das uvas.

\begin{tabular}{|c|c|c|c|c|c|}
\hline & Início do 10 Dia & Início do 2음a & $\begin{array}{l}\text { Início do 3으 } \\
\text { Dia }\end{array}$ & $\begin{array}{l}\text { Início do 4을 } \\
\text { Dia }\end{array}$ & $\begin{array}{l}\text { Fim do 40 } \\
\text { Dia }\end{array}$ \\
\hline Massa total (g) & 961 & 641,5 & 399 & 264 & 201 \\
\hline Massa úmida (g) & 827,42 & 507,92 & 265,42 & 130,42 & 67,42 \\
\hline Massa Seca (g) & 133,58 & 133,58 & 133,58 & 133,58 & 133,58 \\
\hline
\end{tabular}

De acordo com os dados demonstrados na Tabela 2, pode-se determinar a perda de massa percentual e a perda de umidade percentual ao fim de cada dia, expostas nas Tabelas 3.

Tabela 3. Perdas de massa e umidade percentuais da uva.

\begin{tabular}{l|c|c}
\hline & Perda de massa percentual & Perda de umidade percentual \\
\hline Ao fim do 10 dia & $33,25 \%$ & $38,61 \%$ \\
\hline Ao fim do 20 dia & $58,48 \%$ & $67,92 \%$ \\
\hline Ao fim do 3ㅇ dia & $72,53 \%$ & $84,24 \%$ \\
\hline Ao fim do 4 dia & $79,08 \%$ & $91,85 \%$ \\
\hline
\end{tabular}

A Tabela 4 apresenta os dados referentes às medições das massas das três amostras $\left(M_{A 1}, M_{A 2}\right.$ e $\left.M_{A 3}\right)$ em gramas relativos ao primeiro e segundo dia de secagem da uva. A Tabela 5 apresenta os dados referentes ao terceiro dia e quarto dia.

Tabela 4. Massas das amostras da uva no primeiro e segundo dia de secagem.

\begin{tabular}{c|r|r|r|r|r|r|r}
\hline \multicolumn{5}{c|}{ Primeiro dia } & \multicolumn{5}{c}{ Segundo dia } \\
\hline Hora & $\mathrm{M}_{\mathrm{A} 1}(\mathrm{~g})$ & \multicolumn{1}{c|}{$\mathrm{M}_{\mathrm{A} 2}(\mathrm{~g})$} & \multicolumn{1}{c}{$\mathrm{M}_{\mathrm{A} 3}(\mathrm{~g})$} & \multicolumn{1}{c}{ Hora } & \multicolumn{1}{c}{$\mathrm{M}_{\mathrm{A} 1}(\mathrm{~g})$} & \multicolumn{1}{c}{$\mathrm{M}_{\mathrm{A} 2}(\mathrm{~g})$} & \multicolumn{1}{c}{$\mathrm{M}_{\mathrm{A} 3}(\mathrm{~g})$} \\
\hline $12: 00$ & 7,73 & 8,35 & 7,68 & $10: 00$ & 5,20 & 5,57 & 5,11 \\
\hline $13: 00$ & 6,53 & 7,14 & 6,61 & $11: 00$ & 4,25 & 4,72 & 4,23 \\
\hline $14: 00$ & 5,81 & 6,40 & 5,77 & $12: 00$ & 3,94 & 4,32 & 3,85 \\
\hline $15: 00$ & 5,20 & 5,57 & 5,11 & $13: 00$ & 3,41 & 3,84 & 3,38 \\
\hline & & & & $14: 00$ & 3,19 & 3,38 & 3,03 \\
\hline
\end{tabular}


Tabela 5. Massas das amostras da uva no terceiro e quarto dia de secagem.

\begin{tabular}{c|r|r|r|r|r|r|r}
\hline \multicolumn{5}{c|}{ Terceiro dia } & \multicolumn{5}{c}{ Quarto dia } \\
\hline Hora & $M_{\mathrm{A} 1}(\mathrm{~g})$ & $\mathrm{M}_{\mathrm{A} 2}(\mathrm{~g})$ & $\mathrm{M}_{\mathrm{A} 3}(\mathrm{~g})$ & \multicolumn{1}{c}{ Hora } & \multicolumn{1}{c}{$\mathrm{M}_{\mathrm{A} 1}(\mathrm{~g})$} & \multicolumn{1}{c}{$\mathrm{M}_{\mathrm{A} 2}(\mathrm{~g})$} & $\mathrm{M}_{\mathrm{A} 3}(\mathrm{~g})$ \\
\hline $12: 00$ & 3,19 & 3,38 & 3,03 & $11: 00$ & 2,03 & 2,18 & 1,96 \\
\hline $13: 00$ & 2,71 & 3,13 & 2,67 & $12: 00$ & 1,43 & 1,77 & 1,34 \\
\hline $14: 00$ & 2,31 & 2,74 & 2,27 & $13: 00$ & 0,93 & 1,43 & 0,91 \\
\hline $15: 00$ & 2,03 & 2,18 & 1,96 & $14: 00$ & 0,72 & 1,13 & 0,62 \\
\hline & & & & $15: 00$ & 0,52 & 0,53 & 0,37 \\
\hline
\end{tabular}

A Tabela 6 apresenta as perdas de massa em porcentagem das amostras da uva ao final de cada dia, facilitando o estudo da secagem dos alimentos e da eficiência do secador.

Tabela 6. Perdas de massa em porcentagem das amostras de uva no final de cada dia.

\begin{tabular}{r|c|c|c}
\hline \multirow{2}{*}{ Dia (final) } & \multicolumn{3}{|c}{ Uva } \\
\cline { 2 - 4 } & $\mathrm{P}_{\mathrm{A} 1}$ & $\mathrm{P}_{\mathrm{A} 2}$ & $\mathrm{P}_{\mathrm{A} 3}$ \\
\hline Primeiro & $32,73 \%$ & $33,29 \%$ & $33,46 \%$ \\
\hline Segundo & $58,73 \%$ & $59,52 \%$ & $60,55 \%$ \\
\hline Terceiro & $73,74 \%$ & $73,89 \%$ & $74,48 \%$ \\
\hline Quarto & $93,27 \%$ & $93,65 \%$ & $95,18 \%$ \\
\hline
\end{tabular}

Nota-se que, ao final do primeiro dia de secagem, as amostras da uva já haviam perdido mais de $30 \%$ da sua massa. A perda de massa total para as três amostras da uva foi superior a $93 \%$, sendo a amostra 3 a que mais sofreu redução de massa, pois o ponto 3 era a saída de ar do secador, sendo assim o ponto que recebia maior quantidade de calor.

Após a secagem dos alimentos foram obtidos bons resultados comprovando a eficiência do secador proposto. Esses resultados estão descritos na porcentagem de massa perdida pela uva na Tabela 3, bem como na foto dos alimentos secos na Figura 6.

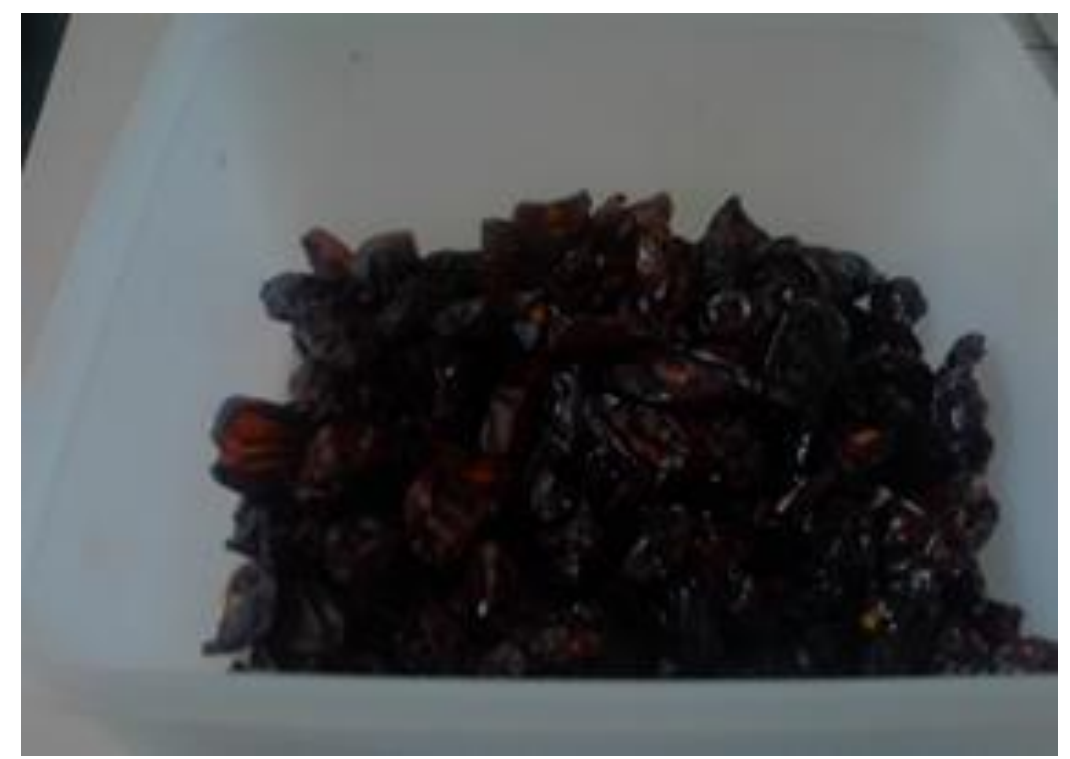

Figura 6. Uva após a secagem.

A Tabela 7 apresenta a massa de água após a secagem da uva, comprovando a eficiência do secador. 
Tabela 7. Massa total, massa úmida inicial e massa úmida final da uva.

\begin{tabular}{l|r}
\hline & Uva \\
\hline Massa total inicial(g) & 961 \\
\hline Massa úmida inicial(g) & 827,42 \\
\hline Massa úmida final (g) & 67,42 \\
\hline Massa úmida final & $8,15 \%$ \\
\hline
\end{tabular}

A massa úmida final da uva ficou abaixo de $10 \%$, como apresentado na Tabela 1 , os valores pretendidos de massa de água final da uva era 15\%, e como apresentado na Tabela 7 , os resultados foram satisfatórios.

Os resultados dos testes realizados demonstraram a viabilidade de utilização dos secadores construídos a partir de sucatas de luminária, podendo a carga dos produtos ser aumentada através da utilização de um maior número de módulos de secagem. 0 tempo de secagem obtido, as umidades finais e as perdas de massa das amostras da uva estiveram compatíveis com o que aponta a literatura especializada em desidratação de alimentos.

Outro fator extremamente positivo no sistema de secagem apresentado é o seu baixo custo e facilidade de construção, podendo contribuir para a socialização da secagem solar como meio de geração de emprego e renda.

\section{CONCLUSÃO}

O secador proposto mostrou-se viável para produzir a secagem do alimento testado a baixo custo, proporcionando seu uso por comunidades carentes visto seu significativo valor agregado em relação aos produtos in natura;

O processo de secagem por exposição direta mostrou-se eficiente podendo produzir perda de massa compatível com o que aponta a literatura especializada em desidratação de alimentos;

O secador proposto é viável para utilização em zona rural e urbana para o combate aos desperdícios e perecibilidade, podendo ser utilizados vários módulos de secadores para o aumento da carga de secagem, além disso o custo de fabricação de tal secador é muito baixo, permitindo assim sua construção por comunidades de baixa renda.

\section{REFERÊNCIAS BIBLIOGRÁFICAS}

1. COSTA, A.R.S., Sistema de secagem solar para frutos e modelagem da secagem de banana em um secador de coluna estática, Tese de Doutorado do Curso de Pós-Graduação em Engenharia Química da UFRN, Natal, RN,2008.

2. FERREIRA, A. G.; et al. Technical feasbility assesment of a solar chimney for food drying. Solar Energy. Vol. 82 p.44-52 (2008).

3. FIOREZE, R. Princípios de secagem de produtos biológicos, João Pessoa. Editora Universitária - UFPB, p.229, 2004.

4. MADAMBA, P.S.; DRISCOLL, R.H.; BUCKLE, K.A. The thin-layer drying characteristics of garlic slices. Journal of Food Engineering v.29, p.75-97, 2007.

5. SANTOS, T.S.N., Estudo comparativo de secadores solares de exposição direta e convectivo, 
Dissertação de Mestrado do Programa de Pós-Graduação em Engenharia Mecânica da UFRN, Natal, RN,1997.

6. SENA, J.F., 1997, Secagem de Sementes de Algodão usando Coletor Solar Plano: Estudo Cinético e Térmico, Dissertação de Mestrado do Programa de Pós-Graduação em Engenharia Mecânica da UFRN, Natal.

7. SOUZA et al, Obtenção de tomate seco utilizando um sistema de secagem solar construído com materiais alternativos, 8 Congresso Iberoamericano de Engenharia Mecânica, Cusco, Peru, 2007.

8. TACO - Tabela brasileira de composição de alimentos / NEPA - UNICAMP.- 4. ed. rev. e ampl.. -- Campinas: NEPA - UNICAMP, 2011. 161 p. 